\title{
GASE REPORT
}

\section{Accidental Ingestion of Irrigation needle during Endodontic Procedure - Use of digital fluoroscopy in management}

\author{
Carounanidy Usha', Sathyanarayanan Ramarao ${ }^{2}$, Mithunjit .S ${ }^{3}$, Sudhagar $\mathrm{M}^{4}$
}

\begin{abstract}
Ingestion of the foreign body like endodontic instrument, mouth mirror top, rubber dam clamp, during root canal treatment are rare but can result in serious complications. The present paper reports a case in which Irrigation needle was accidentally swallowed by the patient undergoing root canal therapy, which entered digestive tract and passed uneventfully within 24 hours.
\end{abstract}

Keywords: Foreign body, Accidental ingestion, Endodontic irrigation needle, Radiography, digital fluoroscopy

\section{Introduction:}

Dental procedures performed inside the oral cavity mandate fine and controlled dexterity to carefully handle the instruments and materials used. Despite appropriate training, accidental slippage of the dental items into the oral cavity is not uncommon. To prevent ingestion or aspiration, barrier techniques such as rubber dam, throat screens etc are strict prerequisites during the procedures [1]. Failure to observe these protocols pose a serious situation for the patient as well the dentist.

According to LI Grossman $87 \%$ of the foreign bodies are ingested and only $13 \%$ is aspirated [2]. Ingested objects though were egested most of the times in these cases, some of them needed removal of the objects either surgically or nonsurgically, aided with imaging techniques. However unlike blunt objects, sharp instruments can lodge and perforate the internal structure of the GI tract resulting in graver complications. The percentage of endodontic instruments aspirated has been reported to be $2.2 \%$ and those that were ingested were $18 \%$ [3]. Majority of these were endodontic hand instruments, such as hand files, rotary files, spreaders etc. But reports on ingestion or aspiration of irrigation needle is sparse in literature [4]. This paper discusses such a rare case of accidental ingestion and uneventful egestion, of irrigation needle during root canal therapy which was started without rubber dam. The purpose of this case report is to highlight the importance of prevention of such hazards by following the simple but stringent protocols of root canal therapy

\section{Case presentation:}

A 62 year old male patient, reported to the Department of Conservative Dentistry \& Endodontics, Indira Gandhi Institute of Dental Sciences, Puducherry, India, with the chief compliant of pain in right lower back teeth region since 3 months. Based on clinical and radiological evidence it was diagnosed as dental caries with irreversible pulpitis and chronic apical periodontitis in 44. Thus root canal therapy was planned and the patient was assigned to a freshly graduated intern. Inferior alveolar nerve block anaesthesia was administered. Access cavity was prepared and canal patency was checked. Rubber dam application was not done. Canal was irrigated with normal saline with a $2 \mathrm{ml}$ hypodermic syringe with 24 gauge friction fit needle. During the procedure the needle separated from the syringe and fell into the floor of the mouth. As the patient had a nerve block anaesthesia, he involuntarily swallowed the endodontic irrigating needle. He complained of immediate gagging along with the sensation of something stuck in his throat. He did not report of further nausea or any pain. He also did not have any difficulty in breathing which provisionally assured that he had swallowed the needle and not aspirated. 
Patient was informed about the accident and was given assurance. He was shifted immediately to the casualty of the attached Medical Hospital in the same campus.

Initial examination was done by the ENT surgeon with laryngoscope which could not detect the foreign body in that location. Later Posteroanterior \& Lateral view of neck, chest, and abdomen radiographs (Fig 1 and 2) were taken which again did not reveal the needle.

A fluoroscopy was suggested by Department of Radiology. This revealed the presence of needle. (Fig 3 )

Fluoroscopy also revealed the swift downward movement of the needle towards the ileum. (Fig 4)

General surgeon opinion was obtained regarding the course of management and it was advised that the patient be kept under observation for 48 hours. Patient was instructed to take easily digestible food. The next day morning, within 24 hours, the needle was excreted in the stool. (Fig 5)

Follow up radiograph were obtained to confirm. (Fig 6)

The patient was asymptomatic. The root canal therapy continued and was completed uneventfully.

\section{Discussion:}

Literature is abundant with reports of ingestion or aspiration of dental related items such as burs [5], posts [3], tooth [6], impression materials [7], implant screws [8], orthodontic brackets [9], mouth mirror top [10], and endodontic instruments [3]. The reasons, however valid they may be, cannot mitigate the legal issues against the operator, simply because these mishaps are easily preventable. In addition to the morbidity that ensues and the mental agony it causes for the patients, it can be life-threatening too. Thus prevention is the first line of treatment.

Application of rubber dam is a pre requisite in root canal therapy. In spite of the well documented uses of rubber dam, a survey study has revealed that more than 60 did not use rubber dam for root canal treatment [11]. It is an excellent barrier technique that protects the soft tissue and prevents the loss of the instruments or materials into the mouth. In addition, rubber dam application is considered crucial during clean and shape phase to prevent contamination. Sometimes access preparation is done before placing the rubber dam to avoid the error of treating the wrong tooth or if the angulation of the crown/ root is different. In the present case, the intern in-charge of the patient was intending the same. The rubber dam was planned during clean and shape phase after checking the patency of the canal. Unfortunately the accident happened during the initial flushing of the canal with saline.

Loss of endodontic instrument is more common than losing an irrigating needle into the mouth mainly due to the size of the irrigating needle. However if an appropriate needle or syringe is not used or if a wrong method of irrigation is adopted, then this accident can occur. Needle separation from the hub of the syringe is more likely with friction fit needles. Separation occurs if the needle is not fitted well into the hub, or if the irrigant is flushed forcefully by tightly wedging the needle into the canal. In this case, a 24 gauge friction fit needle was used. Considering the large canal diameter of a lower premolar, the reason for separation in this case would be loose fit of the needle to the syringe rather than tight wedging of the needle in the canal. In addition, the needle should be bent at 45 degree angulation along the length of the needle, not at the junction of the hub. In the present case, the needle was bent at the hub, which could be another reason for easy separation from the syringe. A luer-lock syringe is safer to be used for endodontic irrigation purposes as it has threads that locks the needle safely $[12,13]$.

Yet another reason for the ingestion of the needle in this patient could be attributed to the anaesthetized tissues [14]. The reflexes could have been reduced due to inferior alveolar nerve block anaesthesia that anesthetizes one half of the lip, tongue and 


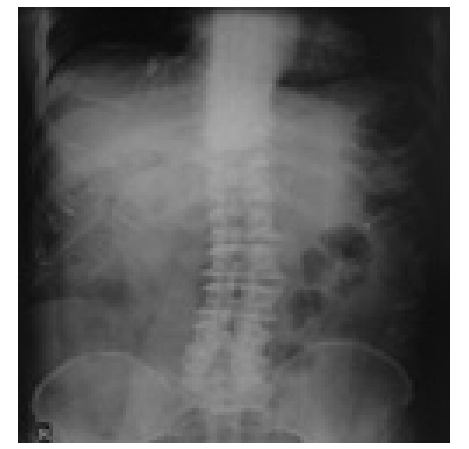

Fig 1: Chest and abdomen $X$ ray

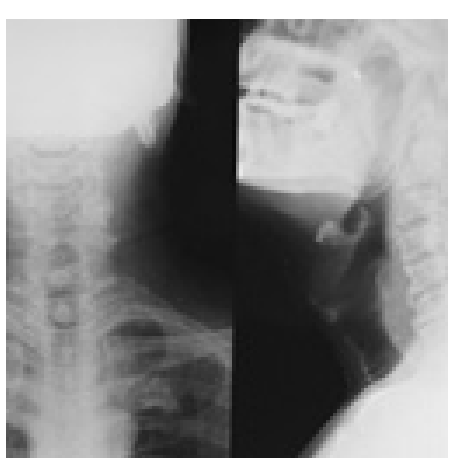

Fig 2: PA and Lateral view of neck and chest

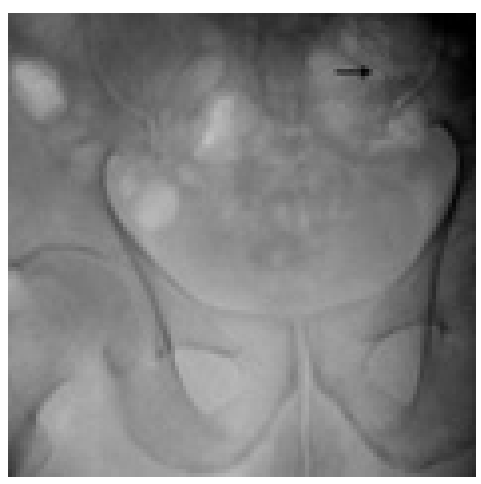

Fig 3: Digital fluoroscopy indicating the needle's position

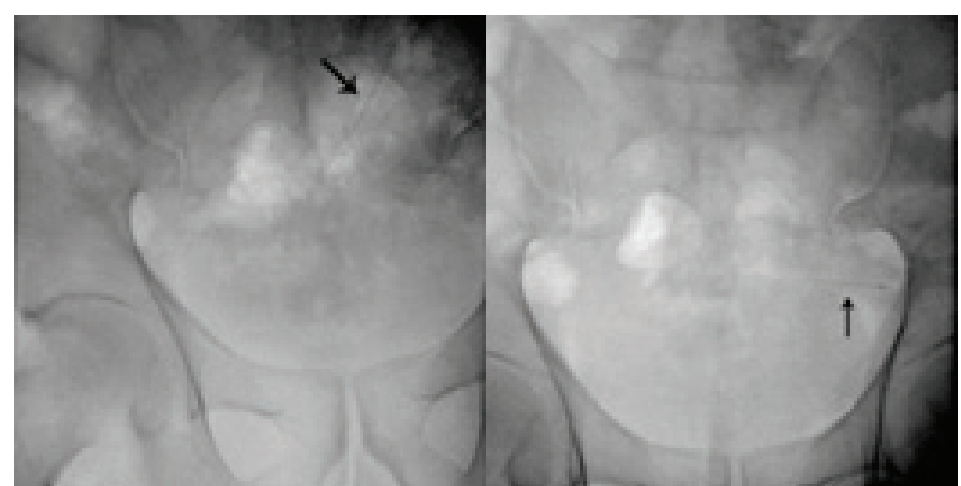

Fig 4: Digital fluoroscopy indicating the needle swiftly moved downwards towards the ileum

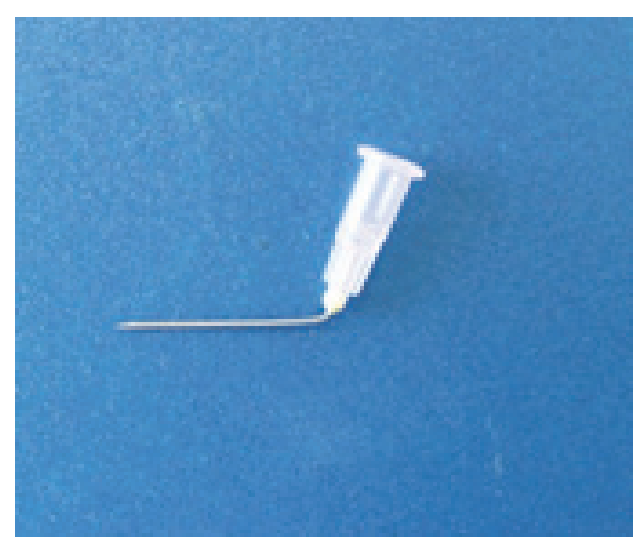

Fig 5: needle retrieved from the stool by the patient

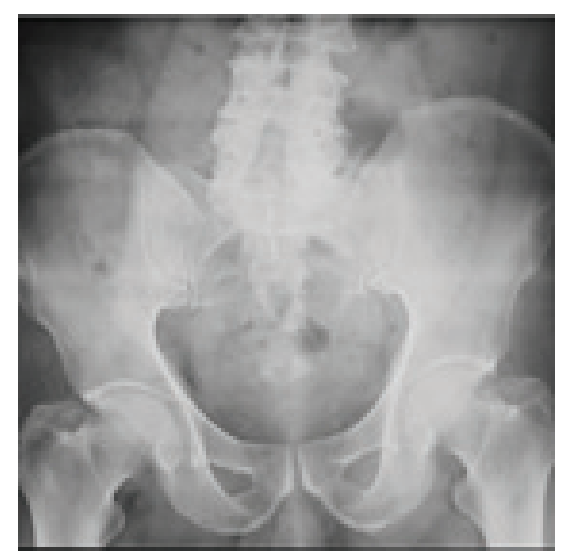

Fig 6: Confirmatory radiograph showing the pelvic view 
floor of the mouth. Lack of quick reflex could also be attributed to the age factor of the patient [15].

Once the foreign object is lost in the mouth, the patient should be placed immediately in a reclined position. Any signs of respiratory distress should be noted to ascertain if the foreign body was lost to the trachea or to the GI tract [9]. This patient did not have respiratory distress, but had mild gagging and a sensation of something struck in his throat. He had no signs of obstruction of oesophagus such as difficulty in swallowing, nausea or pain. Thus it was construed that the needle was not aspirated but ingested.

Ascertaining the location of the foreign body is the next important step. Radiographic examination with PA view and Lateral view of neck, chest and abdomen is mandatory. Other diagnostic methods reported in the literature include computed tomography, magnetic resonance imaging, fluoroscopy and endoscopy. Sharp instruments are generally not visible in radiograph. Thus it is suggested that a laryngoscopic/ endoscopic assessment accompanies the routine radiographs [16]. Our patient was quickly checked with laryngoscopy by the ENT surgeon as well as radiographs were taken. Both investigations did not reveal the needle.

The chair-side was searched again to reconfirm the loss of needle into the mouth. If the foreign body is not identified immediately, it has been suggested that periodic radiographs may be taken. In the current scenario, the radiologist suggested the use of Digital fluoroscopy owing to the reduced radiodensity of the hub and the needle. Plastics are better visualized with this technique. It also provides a real time picture of the place and movement of the foreign body [17]. The fluoroscopy clearly captured the movement of the needle towards the ileum, in this case.

Once its location is identified, it becomes imperative to decide whether to intervene or observe. Intervention to retrieve the foreign body can be surgical or non-surgical. Non-surgically, the retrieval has successfully been done in many cases using endoscopy. Few cases required surgical removal. Most of the ingested items into the stomach have been excreted uneventfully $[18,16]$. Endodontic instruments have been reported to have been egested within 3 days without any complication [19]. It has been stated that foreign object may also be observed with radiographs to track its movement for 3 days. Even after three days, if there is no progress, then surgical intervention is planned. The factors that determine this decision to observe/ intervene surgically or non-surgically depends upon the location of the object and the severity of the signs and symptoms.

Two main complications occur with ingested sharp items, namely, oesophageal obstruction and GI tract perforation. Oesophageal obstruction is an acute emergency that requires the immediate retrieval of the instruments with endoscopy. After passing through the oesophagus, it generally has smooth transit till it reaches the ileo-cecal junction, where the risk of perforation is more, with subsequent abscess formation, haemorrhage, or fistula. When signs of perforation is detected, immediate surgical intervention has been suggested $[16,20]$.

In this patient in concern, as the needle was seen reaching the ileum swiftly in fluoroscopy imaging, the General Surgeons suggested to adopt a careful observation for 24 hour, with repeated radiographs. The patient was advised to be on easily digestible diet and check his stool for the needle. He was also counselled to contact immediately if any abdominal pain developed. The next day the patient reported with the needle that he found in his morning stool. Follow-up radiographs were done to confirm the excretion of the needle. The patient was asymptomatic. His co-operation was commendable and it was acknowledged by the operators.

Immediate recognition of the problem and swift management as depicted in the flow chart (Fig 7) is essential for the effective management of ingested sharp foreign objects $[9,18]$. 


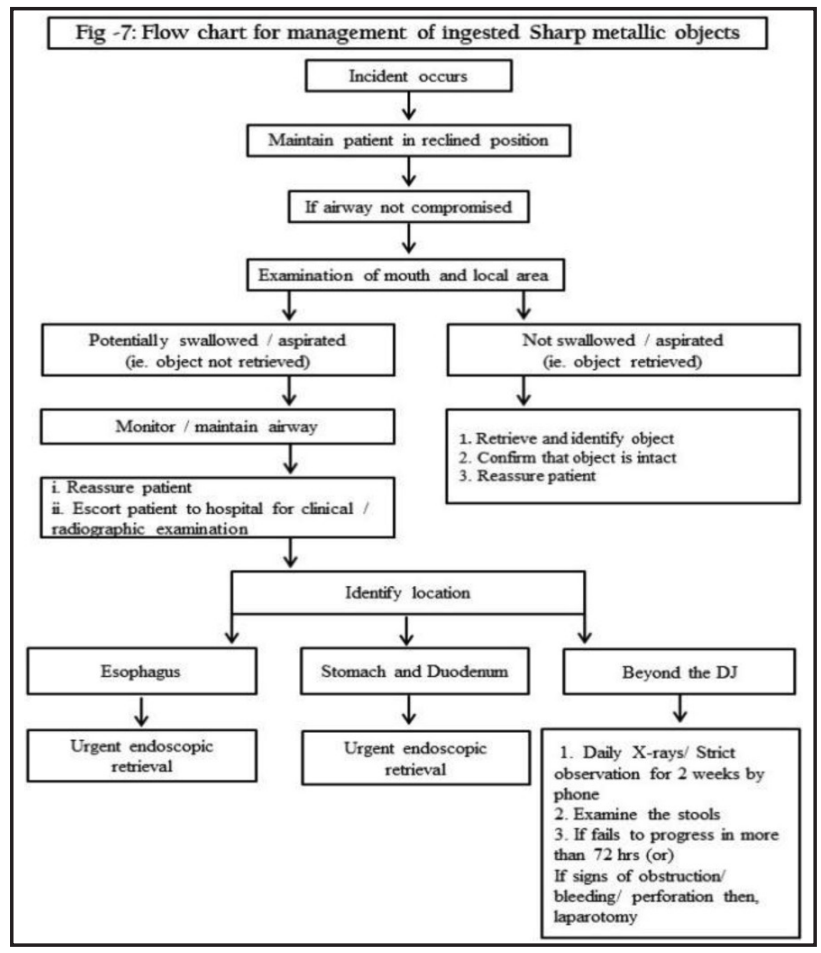

\section{References}

1. Cameron SM, Whitlock WL, Tabor MS. Foreign body aspiration in dentistry; a review. J Am Dent Assoc 1996;127(8):1224-29.

2. Grossman LI. Prevention in endodontic practice. J Am Dent Assoc. 1971;82(2):395-6.

3. Susini G, Pommel L, Camps J. Accidental ingestion and aspiration of root canal instruments and other dental foreign bodies in a French population.

IntEndodont J 2007;40(8):585-89.

4. Srivastava N. Accidental swallowing of the hypodermic needle. Int J ClinPediatr Dent 2009; 2(2): $60-2$.

5. Amarlal D, Jeevarathan J, Muthu MS, Venkatachalapathy A, RathnaPrabhu V. Iatrogenic accidental ingestion of a dental bur. Indian J Pediatr 2009;76(3):333-4.

6. Ospina JC, Ludemann JP.Aspiration of an extracted molar: case report. J Can Dent Assoc. 2005;71(8):581-3.

7. Dent L, Peterson A, Pruett D, Beech D. Dental impression material: a rare cause of small-bowel obstruction. J Natl Med Assoc 2009;101(12):1295-6.
8. Lana R, Mendoza JL. Accidental ingestion of unusual metallic foreign body. Rev EspEnferm Dig 2004;96(12):874-5.

9. Milton TM, Hearing SD, Ireland J. Ingested foreign bodies associated with orthodontic treatment: report of three cases and review of the ingestion/ aspiration incident management. Br Dent J 2001;190(11):59296.

10. Oncel M, Apiliogullari B, Cobankara FK, Apigullari S. Accidental swallowing of the head of a dental mirror; report of a rare case. J Dent Sci 2012;7:199202.

11. Ahmad IA. Rubber dam usage for endodontic treatment: a review. IntEndod J 2009; 42(11):963-72.

12. Clarkson RM, Moule AJ. Sodium hypochlorite and its use as an endodontic irrigant Aust Dent J 1998;43:(4):250-6.

13. Haapasalo M, Shen Y, Qian W, Gao Y. Irrigation in Endodontics. Dent Clin N Am2010;54: 291-312.

14. Mohan R, Rao S, Benjamin M, Bhagavan RK. Accidental ingestion of a barbed wire broach and its endoscopic retrieval: Prevention better than cure. Indian J Dent Res 2011;22:839-42.

15. Ashley J, Duggan M, Sutcliffe N. Speech, Language, and Swallowing Disorders in the Older Adult. ClinGeriatr Med 2006;22:291 - 310 .

16. Ikenberry SO et al. Management of ingested foreign bodies and food impactions. Guideline. Communication from the ASGE standards of Practice Committee. Gastrointestinal endoscopy 2011;73(6):1085-91.

17. Stone DB, Scordino DJ. Foreign Body Removal. In. Roberts and Hedges' Clinical Procedures in Emergency Medicine. Eds. Roberts JR, Custalow CB, Thomsen TW. 6th ed. 2013.WB Saunders.

18. Bisharat M, O'Donnell ME, Gibson N, Mitchell M, Refsum SR, Carey PD, Spence RA, Lee J. Foreign body ingestion in prisoners - The Belfast experience. Ulster Med J. 2008;77(2):110-4.

19. Kuo SC, Chen YL. Accidental swallowing of an endodontic file. IntEndod J 2008;4:617-22. 
20. Umesan UK, Chua KL, Balakrishnan P. Prevention and management of accidental foreign body ingestion and aspiration in orthodontic practice. TherClin Risk Manag. 2012;8:245-52.

\section{Address of Correspondence}

Dr. Carounanidy Usha,

Dept. of Conservative Dentistry and Endodontics, Indira Gandhi Institute of Dental Sciences, Sri Balaji Vidyapeeth Pondy-Cuddalore main Road Pillayarkuppam Puducherry - 607402 India Email id: principal@igids.ac.in usha.c.sathya@gmail.com

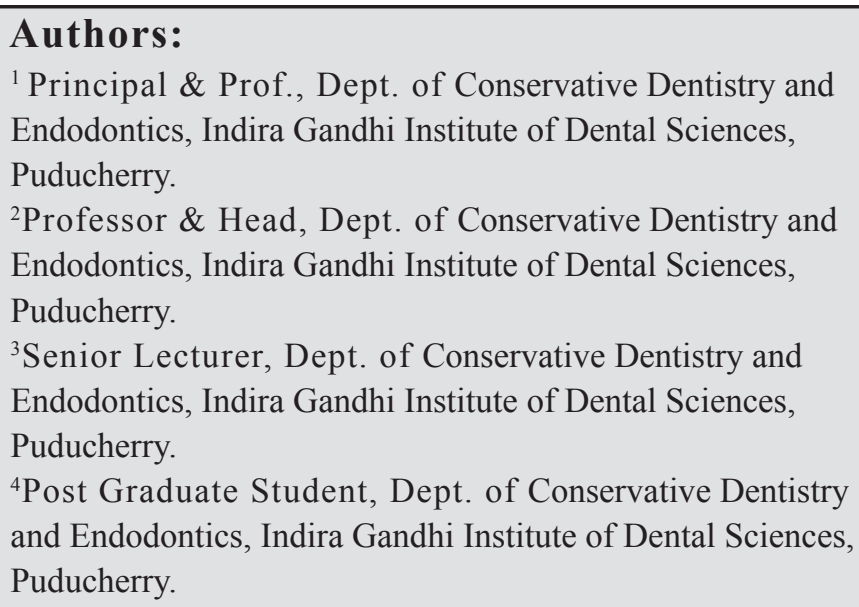

How to cite this article :

Carounanidy Usha, Sathyanarayanan Ramarao, Mithunjit .S, Sudhagar M. Accidental Ingestion of Irrigation needle during Endodontic Procedure - Use of digital fluoroscopy in management. Journal of Scientific Dentistry $2015 ; 5(1): 46-51$

Source of Support : Nil, Confliet of Interest : None declared 